\title{
Mitochondrial Dysfunction Combined with High Calcium Load Leads to Impaired Antioxidant Defense Underlying the Selective Loss of Nigral Dopaminergic Neurons
}

\author{
Konrad M. Ricke, ${ }^{1 *}$ Thomas Paß, ${ }^{1 *}$ Sammy Kimoloi, ${ }^{1}$ Kai Fährmann, ${ }^{1}$ Christian Jüngst, ${ }^{2}$ Astrid Schauss, ${ }^{2}$ \\ Olivier R. Baris, ${ }^{1}$ Marijana Aradjanski, ${ }^{2,3}$ Aleksandra Trifunovic, ${ }^{2,3,4}$ Therese M. Eriksson Faelker, ${ }^{2}$ Matteo Bergami, ${ }^{2,4}$ \\ and $₫$ Rudolf J. Wiesner ${ }^{1,2,4}$ \\ ${ }^{1}$ Center for Physiology and Pathophysiology, Institute of Vegetative Physiology, ${ }^{2}$ Cologne Excellence Cluster on Cellular Stress Responses in Aging- \\ associated Diseases (CECAD), ${ }^{3}$ Institute for Mitochondrial Diseases and Aging, Medical Faculty, and ${ }^{4}$ Center for Molecular Medicine Cologne, University of \\ Köln, 50931 Köln, Germany
}

Mitochondrial dysfunction is critically involved in Parkinson's disease, characterized by loss of dopaminergic neurons (DaNs) in the substantia nigra (SNc), whereas DaNs in the neighboring ventral tegmental area (VTA) are much less affected. In contrast to VTA, SNc DaNs engage calcium channels to generate action potentials, which lead to oxidant stress by yet unknown pathways. To determine the molecular mechanisms linking calcium load with selective cell death in the presence of mitochondrial deficiency, we analyzed the mitochondrial redox state and the mitochondrial membrane potential in mice of both sexes with genetically induced, severe mitochondrial dysfunction in DaNs (MitoPark mice), at the same time expressing a redox-sensitive GFP targeted to the mitochondrial matrix. Despite mitochondrial insufficiency in all DaNs, exclusively SNc neurons showed an oxidized redox-system, i.e., a low reduced/oxidized glutathione (GSH-GSSG) ratio. This was mimicked by cyanide, but not by rotenone or antimycin A, making the involvement of reactive oxygen species rather unlikely. Surprisingly, a high mitochondrial inner membrane potential was maintained in MitoPark SNc DaNs. Antagonizing calcium influx into the cell and into mitochondria, respectively, rescued the disturbed redox ratio and induced further hyperpolarization of the inner mitochondrial membrane. Our data therefore show that the constant calcium load in SNc DaNs is counterbalanced by a high mitochondrial inner membrane potential, even under conditions of severe mitochondrial dysfunction, but triggers a detrimental imbalance in the mitochondrial redox system, which will lead to neuron death. Our findings thus reveal a new mechanism, redox imbalance, which underlies the differential vulnerability of DaNs to mitochondrial defects.

Key words: mitochondria; Parkinson's disease; selective vulnerability; aging; calcium handling; redox stress

Significance Statement

Parkinson's disease is characterized by the preferential degeneration of dopaminergic neurons (DaNs) of the substantia nigra pars compacta $(\mathrm{SNc})$, resulting in the characteristic hypokinesia in patients. Ubiquitous pathological triggers cannot be responsible for the selective neuron loss. Here we show that mitochondrial impairment together with elevated calcium burden destabilize the mitochondrial antioxidant defense only in SNc DaNs, and thus promote the increased vulnerability of this neuron population.

\section{Introduction}

The motor symptoms of Parkinson's disease (PD) are caused by the selective degeneration of dopaminergic neurons (DaNs) in the substantia nigra pars compacta (SNc; Dauer and Przedborski, 2003; Sulzer, 2007; Obeso et al., 2017). Mitochondrial dysfunc-

\footnotetext{
to M.B. and A.T.; and by ERC StG 2015 (Grant 677844) to M.B. Isradipine was kindly provided by Novartis International. We thank Natalie Barthel for her help with oxygen consumption experiments, Johannes Neuhaus for helpful discussions during the course of this study, and N. G. Larsson (Cologne) and J. D. Surmeier (Chicago) for generously providing mouse strains.

The authors declare no competing financial interests.

*K.M.R. and T.P. contributed equally as co-first authors.

Correspondence should be addressed to Rudolf J. Wiesner at rudolf.wiesner@uni-koeln.de or Konrad M. Ricke at kricke@uottawa.ca.

https://doi.org/10.1523/JNEUROSCI.1345-19.2019

Copyright $\odot 2020$ the authors
} 
tion is a central feature of idiopathic PD, but also a large percentage of genetic forms is due to mutations of proteins involved in quality control of the mitochondrial pool (Pickrell and Youle, 2015).

The probability to develop idiopathic PD strongly increases with age (de Lau and Breteler, 2006). At the same time, dopaminergic midbrain regions are hot spots for the accumulation of mitochondrial DNA (mtDNA) deletions (Cortopassi et al., 1992; Meissner et al., 2008), which reach detrimental levels in single DaNs with increasing age (Bender et al., 2006; Kraytsberg et al., 2006; Dölle et al., 2016). Thus, it is tempting to speculate that these two aging-related phenomena are causally connected. We have shown that it is catecholamine metabolism, which drives the enhanced generation of mtDNA deletions (Neuhaus et al., 2014, 2017), and leads to mitochondrial dysfunction (Burbulla et al., 2017), explaining why cells producing dopamine are mostly affected by these mtDNA alterations.

Although there is a general aging-related decline of neurons in the $\mathrm{SNc}$, surprisingly the DaNs in the neighboring ventral tegmental area (VTA) are more or less spared (Reeve et al., 2014), although we have clearly shown that they also accumulate mtDNA deletions (Neuhaus et al., 2014). This specific decline can be further observed in PD patients (Hirsch et al., 1988; Damier et al., 1999), as well as in rodents, where the same specific neuron loss is induced by mitochondrial toxins like MPTP (German et al., 1992) or rotenone (Betarbet et al., 2000). Several reasons have been proposed to explain this puzzling differential vulnerability. One hypothesis is that DaNs of the SNc are unusually large neurons with an extremely branched axonal network that connects to a very high number of other nerve cells. These axonal branches are even unmyelinated (Braak et al., 2004), thus the energy demand to maintain ion homeostasis for action potential propagation and to supply synaptic processes is extremely high (Bolam and Pissadaki, 2012; Pacelli et al., 2015). Liss and Roeper (2008), on the other hand, have shown that this metabolic "stress" triggers activity of K-ATP channels and NMDA receptors, promoting action potential bursting in vivo and propelling excitotoxicity, but only in SNc DaNs (Schiemann et al., 2012; Duda et al., 2016), because in VTA DaNs, mitochondria are mildly uncoupled, potentially preventing K-ATP channel-mediated vulnerability (Liss et al., 2005). Last but probably most attractive, the differential vulnerability of VTA and SNc neurons has been linked to their different modes of pacemaking: Whereas SNc DaNs use L-type calcium channels as well as sodium channels (Chan et al., 2007; Philippart et al., 2016; Ortner et al., 2017), VTA neurons exclusively use sodium channels (Betarbet et al., 2000). Therefore, the maintenance of steep calcium concentration gradients across membranes may again place a much higher energy demand on SNc DaNs. Moreover, their well known low intrinsic calcium buffering capacity (German et al., 1992; Damier et al., 1999; Schiemann et al., 2012), together with $\alpha$-synuclein- and L-type calcium channel-dependent increase in cytosolic calcium (Lieberman et al., 2017) causes "oxidant stress" in mitochondria of vulnerable SNc DaNs, promoting their specific death (Guzman et al., 2010; Dryanovski et al., 2013).

To further explain why two closely related neuron subtypes respond so differently to mitochondrial dysfunction, we investigated the changes in their mitochondrial redox state and inner membrane potential, respectively, in vivo. To achieve this, we targeted a redox-sensitive GFP to the matrix (mito-roGFP; Guzman et al., 2010) in MitoPark mice. MitoPark mice display COX deficiency in DaNs (12 weeks) followed by degeneration of the dopaminergic system and motor impairment, which becomes more pronounced with increasing age (from 13 to 20 weeks; Ekstrand et al., 2007). The mito-roGFP probe is sensitive to the ratio of reduced/oxidized glutathione (GSH/GSSG; Dooley et al., 2004) in the mitochondrial matrix, which in turn depends on the NAD$(\mathrm{P}) \mathrm{H}-\mathrm{NAD}(\mathrm{P})^{+}$ratio (Nelson and Cox, 2005), which again is closely linked to respiratory chain activity.

\section{Materials and Methods}

Experimental model. Experiments were performed in agreement with European and German guidelines and approved (LANUV NRW, Recklinghausen, Germany; 84-02.04.2013-A141). All experiments were performed with male or female mice of the strain C57BL/6N. Tfam ${ }^{\text {loxP/loxP }}$ and Dat-cre mice were provided by Nils-Göran Larsson (Max-Planck-Institute for Biology of Aging, Köln, Germany). MitoPark mice (Tfam ${ }^{\text {loxP/loxP }}+/$ Dat-cre) were bred as described previously (Ekstrand et al., 2007) and $\mathrm{Tfam}^{\text {loxP/WT}}$ or Tfam ${ }^{\text {loxP } / \text { loxP }}$ mice were used as controls. Mito-roGFP mice were provided by James D. Surmeier (Northwestern University Feinberg School of Medicine, Chicago IL). MitoPark $\times$ mito-roGFP mice were generated by crossing Tfam ${ }^{\operatorname{lox} P / W T}+/$ Dat-cre mito-roGFP males with Tfam ${ }^{\text {loxP/loxP }}$ females.

Genotyping. All genetic lines were identified by qualitative PCRapproaches using genomic DNA either from tail tip or ear punch biopsies. Tissue lysis was done in $75 \mu \mathrm{l}$ of lysis buffer $(10 \mathrm{~mm} \mathrm{NaOH}, 0.2 \mathrm{~mm}$ EDTA) at $96^{\circ} \mathrm{C}$ for $45 \mathrm{~min}$. After adding $75 \mu \mathrm{l}$ of neutralization buffer ( 40 $\mathrm{mm}$ Tris- $\mathrm{HCl}, \mathrm{pH}$ 7.6), lysates were centrifuged ( $1 \mathrm{~min}, 3000 \mathrm{rpm}$ ) and stored at $-20^{\circ} \mathrm{C}$. Cycling conditions and primer sequences for the genetic lines are available upon request. Agarose gels containing 1.2 or $1.5 \%$ agarose (Tfam PCR: 1.5\%, DatCre and mito-roGFP PCR: 1.2\%) and 0.8 $\mu \mathrm{g} / \mathrm{ml}$ ethidium bromide in TAE buffer ( $40 \mathrm{~mm}$ Tris base, $20 \mathrm{~mm}$ acetic acid, 1 mm EDTA, pH 8) were used to illustrate PCR products under UV light.

Histology. All immunohistochemical approaches were performed on 5 $\mu \mathrm{m}$ paraffin sections. Striatal tyrosine hydroxylase $(\mathrm{TH})$ immunoreactivity was done using a TH antibody (polyclonal rabbit, Abcam, ab112; $1: 750$ ) and a biotinylated secondary antibody (donkey anti-rabbit, dianova, 111-065-006; 1:500). Fluorescence stainings of midbrain sections were performed with primary antibodies against TH (polyclonal rabbit, Abcam, ab112; 1:1500), mitochondrial complex IV SU1 (COX I, monoclonal mouse, Abcam, ab14705; 1:1000) or calbindin-D28k (Cb-D28k, monoclonal mouse, Swant, 300; 1:150) and fluorochrome-conjugated secondary antibodies (Goat anti-rabbit TRITC-conjugated, AffiniPure, 111-025-144; 1:2000, Goat anti-mouse DyLight488-conjugated, Jackson ImmunoResearch, 115-485-003; 1:400). Visualization of cytochrome $c$ oxidase (COX) deficiency was performed by COX-succinate dehydrogenase $(\mathrm{SDH})$ enzymatic activity staining at bregma $-3.08 \mathrm{~mm}$ similar to Lotter et al. (2017), but incubation with SDH solution was performed for $180 \mathrm{~min}$.

Bright-field microscopy was done with a slide scanner (SCN400, Leica) equipped with a $40 \times$ objective. TH-positive striatal fiber density was determined by optical density analysis using ImageJ software with two sections/mouse at bregma $+0.74 \mathrm{~mm}$. Fluorescence images were obtained with an inverse confocal microscope (TCS SP8 gSTED, Leica) with a $10 \times$ objective $(\mathrm{Cb}-\mathrm{D} 28 \mathrm{k})$ or a $40 \times$ oil objective $(\mathrm{COX})$ at bregma $-3.08 \mathrm{~mm}$. COX-signal intensity was measured in the perikarya of THpositive neurons and normalized to the COX-signal of a TH-negative area. $\mathrm{Cb}-\mathrm{D} 28 \mathrm{k}$ and $\mathrm{TH}$ double stainings were done on two midbrain sections/mouse, followed by identification of double-positive and THpositive neurons similar to the method by Liang et al. (1996).

Two-photon laser scanning microscopy. Two-photon laser scanning microscopy (2PLSM) recordings were performed in $300-\mu \mathrm{m}$-thick coronal midbrain sections. Ten- to 12 -week-old mice were anesthetized with isoflurane and afterward decapitated. The brain was quickly removed and brain sections were prepared with a vibratome (Leica VT1000 S or ThermoFisher Scientific HM $650 \mathrm{~V}$ ) in ice-cold, carbonated artificial CSF (ACSF; in mM: $125 \mathrm{NaCl}, 2.5 \mathrm{KCl}, 25 \mathrm{NaHCO}_{3}, 1.25 \mathrm{NaH}_{2} \mathrm{PO}_{4} \times \mathrm{H}_{2} \mathrm{O}$, 25 glucose, $\left.2 \mathrm{MgCl}_{2}, 2 \mathrm{CaCl}_{2} \times 2 \mathrm{H}_{2} \mathrm{O}\right)$.

2PLSM analysis was adapted from Guzman et al. (2010). Ex vivo 2PLSM measurements in midbrain sections were conducted using a twophoton excitation microscope (TCS SP8 MP-OPO, IR APO L25×/0.95 
objective, Leica). Before recordings, sections were incubated for at least $20 \mathrm{~min}$ at room temperature. Sections were transferred into the recording chamber of the imaging setup containing $\sim 0.5 \mathrm{ml} \mathrm{ACSF}\left(37^{\circ} \mathrm{C}\right)$ and continuously perfused with carbonated ACSF. Solutions were applied at a flow rate of 4-5 $\mathrm{ml}$ per minute. Analysis of the mitochondrial redox ratio in intact cells is enabled by the use of a redox-sensitive variant of the green fluorescent protein (roGFP; Vevea et al., 2013). In the analyzed mouse line, expression of mito-roGFP is driven by the TH promoter (Guzman et al., 2010; Dryanovski et al., 2013), restricting the origin of any mito-roGFP signal to dopaminergic neurons. SNc and VTA DaNs were identified according to their location in the slice. Mito-roGFP excitation was done with $920 \mathrm{~nm}$ wavelength (Chameleon Vision II, Coherent) and fluorescence detection between 500 and $550 \mathrm{~nm}$. Fluorescence intensity in perikarya of single cells was measured using ImageJ software. The fluorescence intensity from a GFP-negative region was subtracted from each DaN signal, to remove mito-roGFP unspecific noise. Previous 2PLSM analysis of mito-roGFP mice (Guzman et al., 2010; Dryanovski et al., 2013) was presented as levels of "relative oxidation" and the mitoroGFP signal was detected on a single focus level, excluding a considerable fraction of the mitochondrial network. Here we analyzed the fluorescence of the entire mitochondrial network in perikarya by stacking $\sim 45$ focus planes ( $z$-stacks; see Fig. 4 , Fig. $4-1$, available at https:// doi.org/10.1523/JNEUROSCI.1345-19.2019.f4-1 and Fig. 4-2, available at https://doi.org/10.1523/JNEUROSCI.1345-19.2019.f4-2). Z-stacks covered a tissue depth of $45 \mu \mathrm{m}$. Neurons that were located at the surface of the slice were excluded from analysis. Discrete mito-roGFP recordings were performed with the multiphoton laser being activated at four time points: (1) at the beginning of the recording $(0 \mathrm{~min}),(2)$ at $20 \mathrm{~min}$ to define the baseline, (3) after application of DTT at $30 \mathrm{~min}$, and (4) after application of aldrithiol (ALD) at $40 \mathrm{~min}$. The fluorescence intensity after DTT application was interpreted as the mito-roGFP response at minimal oxidation or maximal reduction (redox ratio $=0$ ). The signal intensity after application of ALD was taken as response at maximal oxidation (redox ratio $=1$ ). The mitochondrial redox ratio of DaNs was calculated using the following formula: redox ratio $=\left(\right.$ roGFP-F $F_{A C S F}, 20$ min -

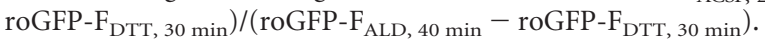

Conditions for tetramethylrhodamine methyl ester (TMRM) 2PLSM recordings for the analysis of the DaN mitochondrial membrane potential were identical to mito-roGFP experiments. Sections were incubated with $100 \mathrm{nM}$ TMRM for $30 \mathrm{~min}\left(37^{\circ} \mathrm{C}\right)$. TMRM recordings were conducted with TMRM-free ACSF. TMRM excitation was performed at 830 $\mathrm{nm}$ with laser intensities between 0.1 to $0.4 \%$ and fluorescence detected at $565-605 \mathrm{~nm}$. DaNs were identified by their mito-roGFP signal elicited with $920 \mathrm{~nm}$. TMRM fluorescence was analyzed sequentially in perikarya of neurons in a fixed-focus level and was detected at the beginning of each session. Only neurons with stable fluorescence traces were considered for TMRM signal quantification. At the end of each recording, sections were perfused with $5 \mathrm{~mm} \mathrm{KCN}$ for $20 \mathrm{~min}$ and the difference between TMRM fluorescence before and after $\mathrm{KCN}$ was calculated $\left(\Delta \mathrm{TMRM}-\mathrm{F}_{\mathrm{KCN}}=\right.$ TMRM-F $\left.\mathrm{F}_{\mathrm{ACSF}}, 20 \mathrm{~min}-\mathrm{TMRM}-\mathrm{F}_{\mathrm{KCN}}, 40 \mathrm{~min}\right)$. Thus, low TMRM signal intensities induced by KCN are reflected by high $\Delta \mathrm{TMRM}-\mathrm{F}_{\mathrm{KCN}}$ values. A high $\triangle$ TMRM- $\mathrm{F}_{\mathrm{KCN}}$ value, in turn, represents a high mitochondrial membrane potential. Background signal was detected by analogous recordings of brain slices without TMRM and subtracted from the TMRM signal emitted by DaNs.

Spherical GFP aggregates were observed in MitoPark mito-roGFP midbrain sections. It was previously reported that these aggregates are mitochondria with a severely disturbed morphology (Sterky et al., 2011). The GFP aggregates in our MitoPark mice were primarily, yet not exclusively, observed in the $\mathrm{SNc}$ and those neurons were excluded from the analysis to eliminate their potential impact on 2PLSM readouts.

For blockade of calcium channels, sections were incubated with 300 nм isradipine or $20 \mu \mathrm{M}$ Ru360 for at least $30 \mathrm{~min}$.

COX-SDH staining. Visualization of COX deficiency was performed by COX-SDH enzymatic activity staining (Sciacco and Bonilla, 1996). COX is a respiratory chain (RC) complex which is partially encoded by mtDNA, whereas SDH, another RC enzyme, is entirely encoded by nuclear DNA. Impaired integrity of mtDNA results in COX deficiency, but sustained SDH activity. Cells with decreased COX activity will stain blue, whereas cells with normal COX activity will appear brown. Mice were killed by cervical dislocation. Following dissection, brains were embedded (OCT, Tissue-Tek), frozen on dry ice and stored at $-80^{\circ} \mathrm{C}$. Cryostat (Leica, CM3050 S) sections of $7 \mu \mathrm{m}$ were stored at $-80^{\circ} \mathrm{C}$. Coronal midbrain cryosections at bregma $-3.08 \mathrm{~mm}$ were air dried and treated with COX incubation solution ( $100 \mu \mathrm{M}$ cytochrome C, $4 \mathrm{~mm}$ diaminobenzidine, $4400 \mathrm{U}$ catalase in $0.1 \mathrm{M}$ phosphate buffer) for $40 \mathrm{~min}$ at $37^{\circ} \mathrm{C}$. Afterward, sections were washed in $\mathrm{dd}_{2} \mathrm{O}(3 \times 30 \mathrm{~s})$ and treated with SDH incubation solution ( $1.5 \mathrm{~mm}$ Nitroblue tetrazolium, $130 \mathrm{~mm}$ sodium succinate, $200 \mu \mathrm{M}$ phenazine methosulfate, $1 \mathrm{~mm}$ sodium azide) for $180 \mathrm{~min}$ at $37^{\circ} \mathrm{C}$. Sections were washed again in $\mathrm{ddH}_{2} \mathrm{O}(3 \times 30 \mathrm{~s})$, dehydrated in $95 \%(2 \times 2 \mathrm{~min})$ and $100 \%$ ethanol (10 min), air dried and mounted with glycerol-gelatin.

Immunohistochemistry. Anesthetized mice (ketamine/xylazine: 100/10 $\mathrm{mg} / \mathrm{kg}$ body weight, i.p.) were intracardially perfused with PBS (Invitrogen; $140 \mathrm{~mm} \mathrm{NaCl}, 10 \mathrm{~mm}$ sodium phosphate, $2.68 \mathrm{~mm} \mathrm{KCl}, \mathrm{pH} 7.4$ ) for $3 \mathrm{~min}$ and 4\% PFA in PBS for $15 \mathrm{~min}$. Brains were dissected and immersion-fixed in 4\% PFA in PBS overnight. Afterward tissues were dehydrated in a series of ethanol solutions (ethanol percentages are given): $70 \%, 90 \%, 2 \times 100 \%$ (15 min each), 100\% (30 min) and 100\% (45 min; Leica ASP300, CMMC Tissue Embedding Facility) and embedded in paraffin (Leica EG1150 H, CMMC Tissue Embedding Facility). Coronal $5 \mu \mathrm{m}$ striatal sections were cut with a microtome (Leica, RM2125 RTS). Sections were deparaffinized in xylene $(2 \times 5 \mathrm{~min})$, washed in a series of ethanol solutions (100, 95, 70, and 50\%, 1 min each) and afterward washed in $\mathrm{dd}_{2} \mathrm{O}$ (5 min). For epitope retrieval, sections were heated in citrate buffer (10 mm citric acid monohydrate, $\mathrm{pH}$ 6) using a microwave oven.

Bright-field microscopy. Sections were washed in TBS (10 mM Tris base, $150 \mathrm{~mm} \mathrm{NaCl}, \mathrm{pH} 7.6,3 \times 5 \mathrm{~min}$ ), quenched with $0.3 \% \mathrm{H}_{2} \mathrm{O}_{2} / \mathrm{TBS}$ solution and washed again in TBS $(3 \times 5 \mathrm{~min})$. Subsequently, sections were blocked in 10\% normal goat serum in TBS ( $45 \mathrm{~min}, \mathrm{RT}$ ) and afterward incubated with the TH antibody (polyclonal rabbit, Abcam, ab112; 1:750 in $3 \%$ skim milk powder/TBS, overnight, $4^{\circ} \mathrm{C}$ ). After another TBS washing step $(3 \times 5 \mathrm{~min})$, sections were incubated with the secondary biotinylated antibody (donkey anti-rabbit, dianova, 111-065-006; 1:500 in 3\% skim milk powder/TBS, $30 \mathrm{~min}$, RT), followed by avidin/biotin Vectastain Elite ABC HRP Kit (Vector Laboratories). Visualization was performed using DAB solution $\left(0.46 \mathrm{~mm} 3,3^{\prime}\right.$-diaminobenzidine tetrahydrochloride, $7.3 \mathrm{~mm}$ imidazole, $15.2 \mathrm{~mm}$ ammonium nickel (II) sulfate hexahydrate, $0.015 \% \mathrm{H}_{2} \mathrm{O}_{2}$ in TBS, $\mathrm{pH} 7.1,6 \mathrm{~min}$ ). Following a short washing in $\mathrm{ddH}_{2} \mathrm{O}(1 \mathrm{~s})$, sections were dehydrated in $50 \%, 70 \%(1 \mathrm{~s}$ each), $95 \%$ and $100 \%$ ethanol $(1 \mathrm{~min}$ each), cleared in xylene $(2 \times 10$ min) and mounted with Entellan.

Fluorescence stainings. Sections were rinsed in $0.2 \%$ Triton X-100 in TBS $(3 \times 5 \mathrm{~min})$ after the epitope retrieval and incubated with the primary antibodies (TH polyclonal rabbit, Abcam, ab112; 1:1500, mitochondrial complex IV SU1 (COX I) monoclonal mouse, Abcam, ab14705; 1:1000 or calbindin-D28k (Cb-D28k) monoclonal mouse, Swant, 300; 1:150 in Dako antibody diluent, overnight, $4^{\circ} \mathrm{C}$ ). Sections were washed in $0.2 \%$ Triton X-100 in TBS $(3 \times 5 \mathrm{~min})$ and incubated with fluorochrome-conjugated secondary antibodies (Goat anti-rabbit TRITC-conjugated, AffiniPure, 111-025-144; 1:2000, Goat anti-mouse DyLight488-conjugated, Jackson ImmunoResearch, 115-485-003; 1:400, overnight, $4^{\circ} \mathrm{C}$ ). Following another washing step in $0.2 \%$ Triton X-100 in TBS $(3 \times 5 \mathrm{~min})$, midbrain sections were counterstained with DAPI ( 1 $\mu \mathrm{g} / \mathrm{ml}$ in $\left.\mathrm{ddH}_{2} \mathrm{O}, 1 \mathrm{~min}\right)$, washed again in $0.2 \%$ Triton X-100 in TBS $(3 \times$ $5 \mathrm{~min}$ ) and mounted with Fluoromount.

Stereological quantification of dopaminergic neurons. For the counting of DaNs, tyrosine hydroxylase stainings of serial coronal paraffin midbrain sections were performed similar to stainings in the striatum. Sections were incubated with DAB solution $\left(0.46 \mathrm{~mm} 3,3^{\prime}\right.$ diaminobenzidine tetrahydrochloride, $7.3 \mathrm{~mm}$ imidazole, $15.2 \mathrm{~mm}$ ammonium nickel (II) sulfate hexahydrate, $0.015 \% \mathrm{H}_{2} \mathrm{O}_{2}$ in TBS, $\mathrm{pH}$ 7.1) for $14 \mathrm{~min}$ and counterstained with nuclear fast red (NFR; $0.1 \%$ in $5 \%$ aluminium sulfate dissolved $1: 5$ in $\mathrm{dd}_{2} \mathrm{O}$ ). Stereological quantification of DaNs was conducted with the physical fractionator approach, which is typically used for the quantification of large neuron numbers in brain nuclei using thin, paired tissue sections (Gundersen et al., 1988; Ma 
et al., 2003; Glaser et al., 2007). The region-of-interest was confined either to the SNc or to the VTA using the mouse brain atlas (Paxinos and Franklin, 2001) on sections between bregma -2.54 and $-3.88 \mathrm{~mm}$. Neurons Q were only counted, if their TH- and NFR-positive profiles appeared in the reference section but not in the lookup section. In addition, neurons had to be located either within the counting frame, or touching the open frame, but not touching the forbidden frame. The height sampling fraction (hsf; section thickness/dissection height $=5 \mu \mathrm{m} / 5 \mu \mathrm{m}=$ 1) and the area sampling fraction (asf; area of counting frame/area of sampling grid $\left.=42.9 \mu \mathrm{m}^{2} / 191.82 \mu \mathrm{m}^{2}=0.223647\right)$ were given as constants. The section sampling fraction (ssf) was set by the number of sections between the analyzed section pairs (typically 21 sections). Total dopaminergic neuron numbers $N$ were calculated by means of the following formula (Dorph-Petersen et al., 2001; Howard and Reed, 2005): $N=\mathrm{Q} \times 1 / \mathrm{hsf} \times 1 /$ asf $\times 1 /$ ssf.

Spontaneous motor activity. Beam break experiments were performed to examine the spontaneous horizontal and vertical movement (rearing behavior) of mice. The activity measurements were done in homemade beam break detector cages. Before the experiments, cages were cleaned with ethanol. Horizontal movement and vertical activity were detected by infrared beams. Interruptions on the horizontal and vertical level were recorded during a tracking period of $60 \mathrm{~min}$. The total counts after 60 min are presented as percentages of control animals. All experiments were conducted between 12:00 and 17:00.

Oxygen consumption measurements. Polarographic measurements were performed in $300-\mu \mathrm{m}$-thick coronal brain sections. Ten- to 20 week-old mice were killed by cervical dislocation and the brain was quickly removed. Sections were prepared with a vibratome (Leica VT1000 S) in ice-cold, carbonated ACSF (in mm: $125 \mathrm{NaCl}, 2.5 \mathrm{KCl}, 25 \mathrm{NaHCO}_{3}, 1.25$ $\mathrm{NaH}_{2} \mathrm{PO}_{4} \times \mathrm{H}_{2} \mathrm{O}, 25$ Glucose, $\left.2 \mathrm{MgCl}_{2}, 2 \mathrm{CaCl}_{2} \times 2 \mathrm{H}_{2} \mathrm{O}\right)$. Tested compounds were dissolved freshly or prepared from stock solutions (stored at $-80^{\circ} \mathrm{C}$ ) on the day of the experiment. Oxygen consumption of midbrain sections was measured at $37^{\circ} \mathrm{C}$ using a Clark-type oxygen electrode (Hansatech oxyview system) in a closed glass chamber containing 1 $\mathrm{ml}$ un-carbonated recording ACSF. An initial zero calibration with sodium dithionite was performed before the measurement. Mitochondrial respiratory chain inhibitors were applied to midbrain sections with a micro syringe. Mitochondrial oxygen consumption was stopped by adding $5 \mathrm{~mm}$ potassium cyanide at the end of the recordings. Relative values of oxygen content given by the measurement were converted into absolute values using reference oxygen values of electrolyte solutions at defined conditions (http://water.usgs.gov/software/DOTABLES/, $37.5^{\circ} \mathrm{C}$ solution temperature, $760 \mathrm{mmHg}$ barometric pressure and $12 \%$ salinity). Mean oxygen consumption was determined over a period of 5-10 min. Oxygen consumption during application of potassium cyanide was averaged over a period of 2 min to measure non-mitochondrial oxygen consumption. After oxygen consumption measurements, midbrain sections were snap frozen in liquid nitrogen and stored at $-20^{\circ} \mathrm{C}$. Brain material was thawed on ice and lysed in TOTEX (20 mm HEPES, $400 \mathrm{~mm} \mathrm{NaCl}, 20 \%$ glycerol, $1 \% \mathrm{NP}-40,1 \mathrm{~mm} \mathrm{MgCl}_{2}, 0.5 \mathrm{~mm}$ EDTA, $0.1 \mathrm{~mm}$ EGTA, $10 \mathrm{~mm}$ $\alpha$-glycerophosphate, 5 mu DTT, 10\% Roche complete Protease Inhibitor, $\mathrm{pH}$ 7.9) buffer with fourfold volume of the sample volume. Lysates were frozen at $-80^{\circ} \mathrm{C}$ to rupture membranes. For the measurement of the protein content, lysates were thawed on ice again, centrifuged (15 $\mathrm{min}, 4^{\circ} \mathrm{C}, 14,000 \mathrm{rpm}$ ) and supernatants were carefully removed. Protein concentrations of the supernatants were determined using Bradford assay with a BSA standard. Oxygen consumption values of midbrain sections were normalized to their protein content and presented as percentages of control measurements. Values of sample size $(n)$ represent the number of investigated brain sections.

Experimental design and statistical analysis. Statistical analysis was done with GraphPad Prism 4. Quantified Data are presented as mean + SEM. Values of sample size $(n)$ refer to mouse numbers or, in COXimmunohistochemistry and in 2PLSM experiments, to neuron numbers. Unpaired $t$ tests, one-way or two-way ANOVA with post hoc comparisons (Kruskal-Wallis with Dunn's or Bonferroni post hoc test) were used to determine differences between groups. A significance level of 0.05 was accepted for all statistical tests. Asterisks mark $P$ values of ${ }^{\star} 0.05,{ }^{* \star} 0.01$, ${ }^{* * *} 0.001$, or ${ }^{* * * *} 0.0001$.

\section{Results}

MitoPark mice recapitulate the differential vulnerability of the dopaminergic system following mitochondrial impairment

In $\mathrm{PD}$ patients, degeneration of dopaminergic projections is primarily observed in the caudate putamen region $(\mathrm{CPu})$ of the striatum (Miller et al., 1997), which is innervated by SNc DaNs (Liss and Roeper, 2008). In contrast, the nucleus accumbens (NAc), which is a major projection area for VTA DaNs, is more or less spared (Miller et al., 1997). A similar pattern of differential fiber loss was also observed in the striatum of MitoPark mice (Fig. $1 A)$. There was no reduction of dopaminergic projections in the NAc of 12- and 14-week-old MitoPark mice (Fig. 1B; 12-weekold MitoPark mice $105 \pm 2 \%$ TH-positive fiber density compared with controls, $p=0.9656$, n.s.; 14-week-old MitoPark mice $104 \pm 3 \%, p>0.9999$, n.s.), and only a minor reduction in 20 -week-old MitoPark mice ( $85 \pm 3 \%$; $p=0.0226$ ). However, there was rapid degeneration of dopaminergic projections in the $\mathrm{CPu}$ : a severe loss of fibers was observed already at 14 weeks (Fig. $1 C$; fibers remaining: $53 \pm 9 \%, p<0.0001)$ and even more at 20 weeks $(16 \pm 3 \%$; $p<0.0001)$ in MitoPark mice, underlining also in this genetic PD model the striking differential vulnerability of dopaminergic projections to mitochondrial dysfunction.

This differential vulnerability was also clearly observed when counting neurons in the midbrain. In aging MitoPark mice, SNc DaNs die earlier than VTA DaNs (Fig. 1D; 20-week-old MitoPark mice: VTA $81 \pm 5 \%$, SNc $32 \pm 3 \%, p=0.0001)$ and neurodegeneration starts at 12 weeks and becomes pronounced at 20 weeks (20 weeks: control SNc $100 \pm 9 \%$, MitoPark SNc $32 \pm 3 \%$, $p<0.0001)$. Nigro-striatal degeneration causes impairment of spontaneous movement, starting at 14 weeks (Fig. $1 E$; horizontal $55 \pm 5 \%, p=0.0040)$. Reflecting the progressive development of the PD phenotype, motor behavior of MitoPark mice was further decreased over time (horizontal: 15 weeks $60 \pm 4 \%, p=0.0067$, 20 weeks $\pm 53 \% 4 \%, p=0.0002$; vertical: 20 weeks $14 \pm 6 \%, p=$ $0.0036)$. Next, we asked whether the selective vulnerability observed in MitoPark mice is because of a different time course in the loss of the RC, which is represented by the mtDNA-encoded subunit I of COX, essential for activity as well as assembly (Fig. $2 A, B)$. Interestingly, somata of DaNs of control mice exhibited a higher COX signal compared with the surrounding tissue (VTA: $134 \pm 15 \%$, SNc: $129 \pm 8 \%$ ). The COX-signal was clearly reduced, however to a similar extent in both, VTA and SNc of MitoPark mice at 12 weeks, at the onset of neurodegeneration (VTA: $72 \pm 2 \%, p<0.0001$; SNc: $66 \pm 2 \%, p<0.0001$ ). In addition, a severe deficiency of enzymatic COX activity was detected by histochemistry in DaNs in the SNc, but, importantly, again similarly in the VTA of MitoPark mice (Fig. 2C). Therefore, both dopaminergic midbrain regions displayed comparable and severe mitochondrial dysfunction, implying that other SNc DaNspecific characteristics must be responsible for their enhanced vulnerability.

\section{Calbindin-D28k expression increases the probability for survival of dopaminergic neurons in MitoPark mice}

The higher vulnerability of SNc DaNs to mitochondrial dysfunction might be linked to differential expression of calcium-binding proteins, since mitochondria are importantly involved in calcium handling. Indeed, in postmortem PD patient samples those midbrain regions which are prone to neurodegeneration contain fewer calbindin-expressing neurons than areas with low susceptibility (Yamada et al., 1990). Therefore, the presence of calbindin was investigated in the surviving fraction of DaNs in MitoPark mice 
A

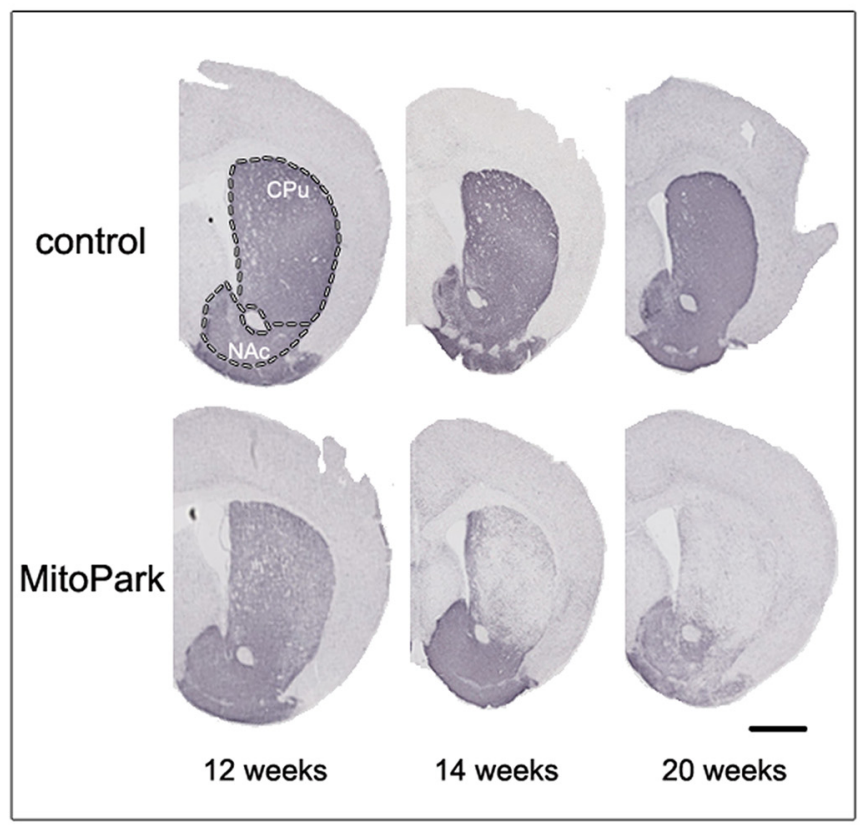

D

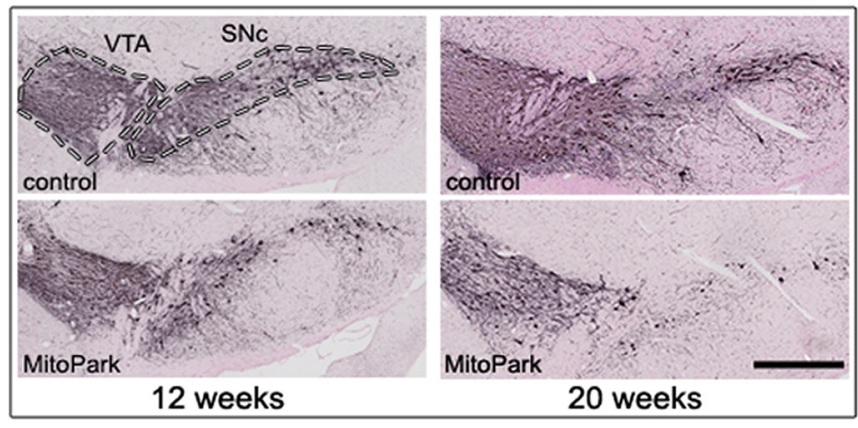

B

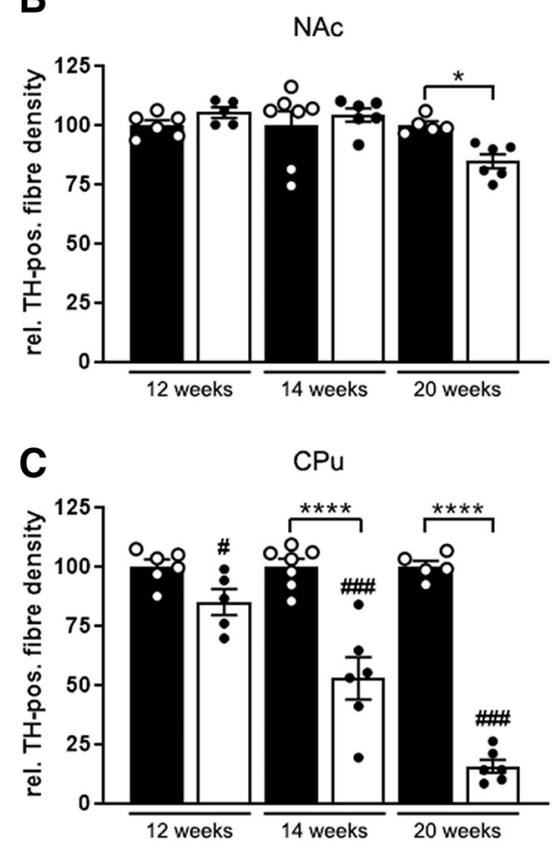

o control

- MitoPark
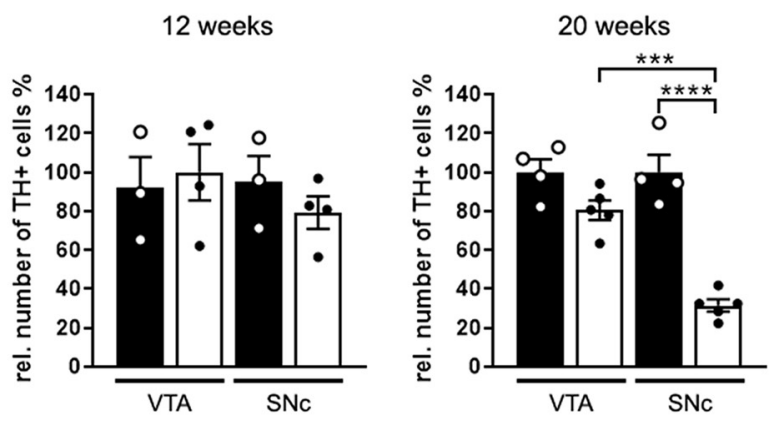

$\mathbf{E}$

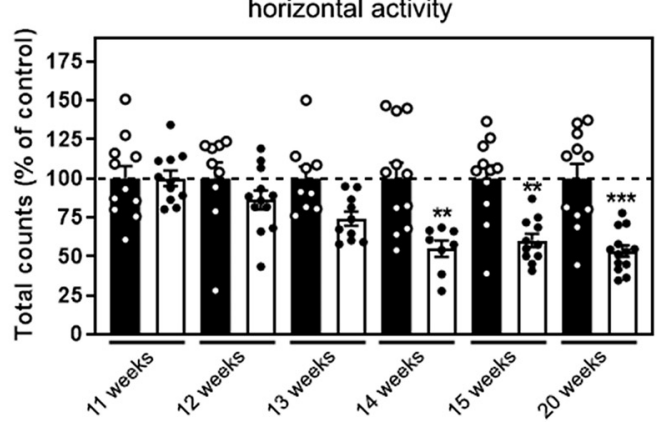

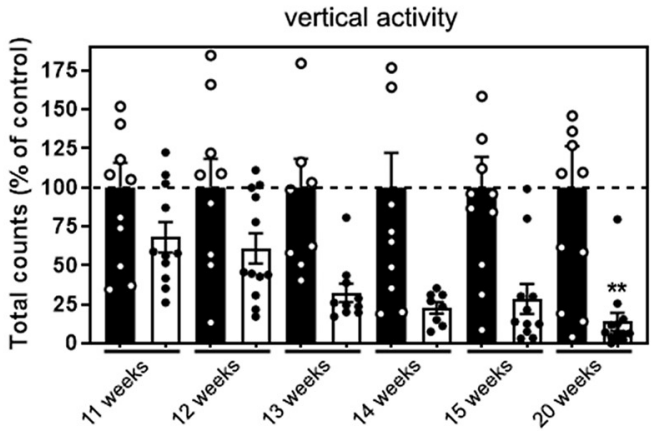

Figure 1. Degeneration of the nigro-striatal system in MitoPark mice. A, Tyrosine hydroxylase (TH) immunohistochemistry in the striatum (CPu and NAC, marked by the dashed line) of 12-, 14-, and 20-week-old MitoPark and age-matched control mice. Scale bar, $1 \mathrm{~mm}$. B, Quantification of the striatal TH signal revealed minor degeneration of dopaminergic projections with increasing age in the NAc of MitoPark mice (black dots on white bars). $\boldsymbol{C}$, In contrast, there was a dramatic loss of the dopaminergic projections in the CPu of aging MitoPark mice (Control mice: $n=5-7$, MitoPark mice: $n=5-6$; \# indicates significances between (Pu and NAc of MitoPark mice). D, Immunohistochemical staining of TH-positive neurons in the VTA and SNcin 12-and 20-week-old MitoPark and control mice (VTA and SNc delimitated by dashed lines). Scale bar, $500 \mu \mathrm{m}$. DaN numbers (TH + neurons) in both midbrain regions of MitoPark (black dots on white bars; $n=4-6$ ) and control mice (white dots on black bars; $n=4$ ) were estimated by stereological quantification. $\boldsymbol{E}$, Beam break events are presented on the horizontal and vertical levels to show the spontaneous motoric activity of MitoPark mice (black dots on white bars; $n=8-13$ ) compared with control mice (white dots on black bars; $n=9-11$ ). Data are represented as mean $\pm S E M ;{ }^{*} p<0.05$, ${ }^{* * *} p<0.01$, ${ }^{* * *} p<$ $0.001,{ }^{* * * *} p<0.0001$, \#\#p $<0.001$.

(Fig. 3A). In the VTA, the proportion of calbindin-positive neurons did not differ between control and MitoPark mice (Fig. 3B; 12 weeks: control $25 \pm 1 \%$, MitoPark $39 \pm 5 \%, p=0.1600$, n.s.; 14 weeks: control $26 \pm 5 \%$, MitoPark $39 \pm 9 \%, p=0.3068$, n.s.; 20 weeks: control $21 \pm 2 \%$, MitoPark $40 \pm 7 \%$; $p=0.0671$, n.s.). In addition, in the VTA the amount of calbindin-positive neurons of control and MitoPark mice did not significantly change over time. However, in the SNc, we observed a higher fraction of re- 
A

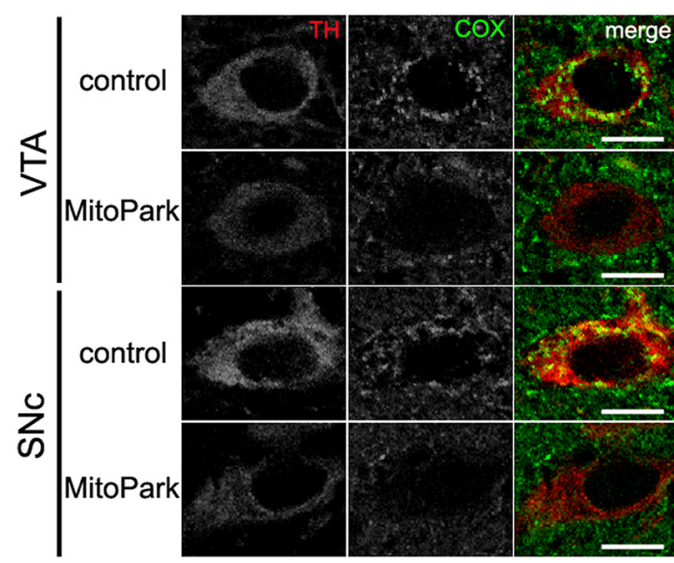

B

C

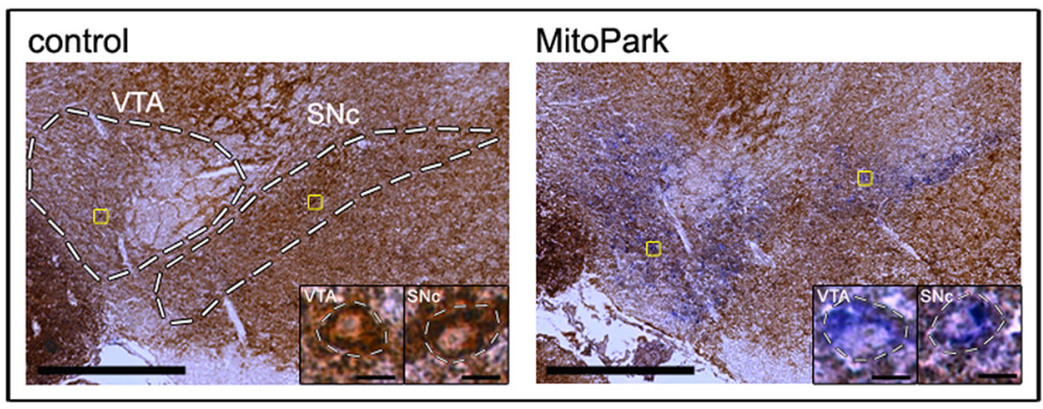

Figure 2. Mitochondrial respiratory chain integrity is lost in dopaminergic neurons of MitoPark mice. $\boldsymbol{A}$, The signal of the COX immunostaining (green) was analyzed in TH-positive (red) neurons in the VTA and the SNc of 12-week-old control and MitoPark mice. Scale bars, $10 \mu \mathrm{m}$. $\boldsymbol{B}$, The fluorescence intensity of the COX-staining (norm. COX-FI) was dramatically decreased in both, VTA and SNc DaNs of MitoPark mice (Control mice: white dots on black bars, $n=21-32$ neurons, 4 mice; MitoPark mice: black dots on white bars, $n=45-47$ neurons, 6 mice). $C$, Neurons with reduced activity of COX in the VTA and the SNc in 12-week-old MitoPark mice were unraveled by COX-SDH staining (dashed lines delimitate the dopamine midbrain regions in the overview with $500 \mu m$ scale bars and single neurons in the close-ups with $10 \mu \mathrm{m}$ scale bars). Data are represented as mean $\pm \mathrm{SEM} ;{ }^{* * *} p<0.0001$.

maining, calbindin-positive DaNs in 20-week-old MitoPark mice compared with controls (control $9 \pm 3 \%$, MitoPark $29 \pm 9 \%$, $p=0.0262$ ), strongly suggesting that the presence of this protein is protective in the context of severe general neuron loss (Fig. 1D).

\section{The inhibition of mitochondrial complex IV increases the redox ratio of $\mathrm{SNc}$ DaNs}

TH-mito-roGFP mice (here referred to as mito-roGFP) express a redox-sensitive GFP variant in the mitochondrial matrix of DaNs, and thus can be used to assess changes of the redox system, more specifically the GSH/GSSG ratio, in situ. Guzman et al. (2010) used this fluorescence sensor to estimate "oxidant stress" of the mitochondrial matrix in DaNs. The reducing compound dithiothreitol (DTT) and the oxidizing compound ALD were sequentially applied during 2PLSM experiments to calibrate the redox-sensitive GFP signal (Guzman et al., 2010; Dryanovski et al., 2013). To optimize our redox calibration protocol, in a first experiment, DTT and ALD were applied to midbrain sections for $10 \mathrm{~min}$ while the 2PLSM laser was inactive (Fig. 4-1, available at https://doi.org/10.1523/JNEUROSCI.1345-19.2019.f4-1). DTT induced a strong increase (VTA: $+0.34 \pm 0.06$ fold-change, SNc: $+0.32 \pm 0.04$ fold-change) and ALD a strong decrease of the fluorescence intensity (VTA: $-0.35 \pm 0.02$ fold-change, SNc: $-0.42 \pm 0.04$ fold-change) measured after this time. Also, application of $\mathrm{H}_{2} \mathrm{O}_{2}$ resulted in a pronounced decrease of the fluorescence intensity in both, VTA $(-0.66 \pm 0.04$ fold-change $)$ and SNc DaNs $(-0.65 \pm 0.03$ fold-change). In addition, a kinetic analysis was performed in 2PLSM experiments with a continuously active laser (Fig. 4-2, available at https://doi.org/10.1523/ JNEUROSCI.1345-19.2019.f4-2). The normalized mito-roGFP fluorescence $\left(F / F_{0}\right)$ displayed a constant loss of intensity over time (Fig. 4-3A, available at https://doi.org/10.1523/JNEUROSCI. 1345-19.2019.f4-3). Application of DTT (Fig. 4-2 B, available at https://doi.org/10.1523/JNEUROSCI.1345-19.2019.f4-2) induced a pronounced increase of the fluorescence intensity which reached a plateau after $10 \mathrm{~min}$ of application $(127 \pm 5 \% ; p<$ $0.001)$. The mito-roGFP signal reached the initial level ( $99 \pm 4 \%$ ) after 10 further minutes of DTT application. A rapid loss of the fluorescence intensity $(46 \pm 2 \%$; $p<0.01)$ was observed when application of DTT was followed by ALD (Fig. 4-2C, available at https://doi.org/10.1523/JNEUROSCI.1345-19.2019.f4-2). Thus, the mito-roGFP signal can be maximally increased by a $10 \mathrm{~min}$ application of DTT and maximally decreased by a consecutive 10 min application of ALD. These application intervals were used in follow-up experiments to gain reference values for signal intensity. Since we observed a permanent signal loss in the continuous recording mode, we evaluated the signal in "discrete" experiments, with the laser being inactive for most of the time. The laser was active at the beginning of the recording $(0 \mathrm{~min})$, at $20 \mathrm{~min}$, after application of DTT at $30 \mathrm{~min}$ and after application of ALD at 40 min (Fig. 4-2D, available at https://doi.org/10.1523/JNEUROSCI. 1345-19.2019.f4-2). The signal loss after 20 min during this protocol was considerably lower compared with continuous recordings (Fig. 4-2E, available at https://doi.org/10.1523/JNEUROSCI. 1345-19.2019.f4-2). Few neurons which displayed a rundown by 
A
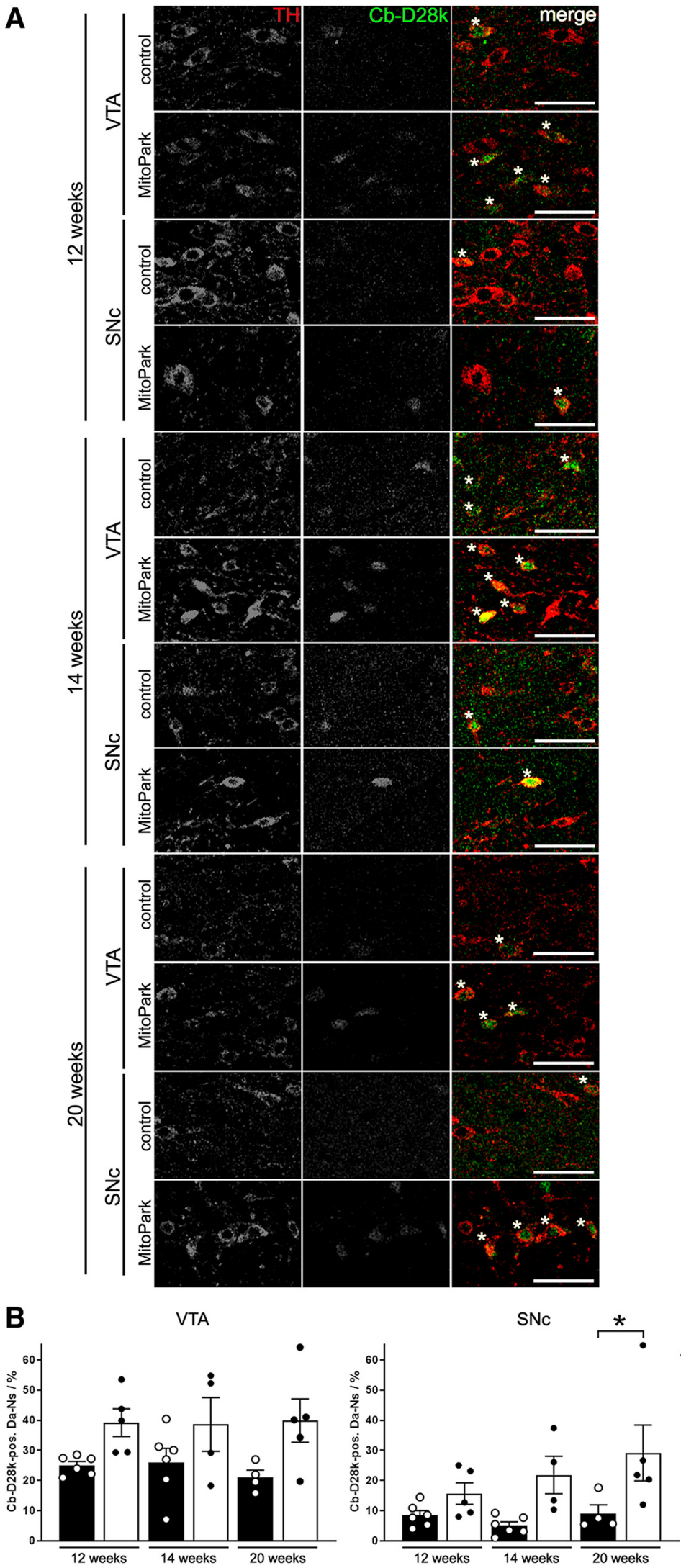

Figure 3. Colocalization of TH and calbindin-D28k (Cb-D28k) in the midbrain of 12-, 14-, and 20-week-old MitoPark mice. $A$ Merged TH (red, 1st column) and Cb-D28k (green, 2nd column) fluorescence immunostainings depict Cb-D28k-expressing DaNs (yellow, marked by asterisks). Scale bar, $50 \mu \mathrm{m}$. B, There were significantly more Cb-D28k-positive DaNs in the SNc of 20-week-old MitoPark mice compared with control mice. Data are represented as mean \pm SEM (Control mice: white dots on black bars, $n=$ $4-6$, MitoPark mice: black dots on white bars, $n=4-5 ;{ }^{*} p<0.05$ ).
$>40 \%$ after 20 min were excluded from analysis. In remaining neurons, DTT and ALD caused prominent changes of the fluorescence intensity (Fig. 4-2D, available at https://doi.org/10.1523/JNEUROSCI. 1345-19.2019.f4-2).

After optimizing the recording conditions, selective RC inhibitors were applied to acute midbrain sections of TH-mitoroGFP wild-type mice to investigate how defects of the RC change the redox-ratio of the glutathione system. To prove their efficiency, we confirmed that Rotenone, antimycin A and potassium cyanide $(\mathrm{KCN})$ significantly reduced oxygen consumption of similarly isolated midbrain sections at the same concentrations used in 2PLSM (Fig. 4-3, available at https://doi. org/10.1523/JNEUROSCI.1345-19.2019. f4-3; rotenone: $36 \pm 3 \%$ of control measurements, $p=0.0019$; antimycin A: $23 \pm$ $3 \%, p=0.0016$; KCN: $6 \pm 2 \%, p<$ $0.0001)$. Rotenone was used at its maximal solubility and a higher concentration of antimycin A $(200 \mu \mathrm{M})$ did not further reduce oxygen consumption (data not shown). Oligomycin at maximal concentration, probably because of its high lipophilicity and the myelin rich brain slice, displayed extremely slow wash in kinetics and did not significantly reduce oxygen consumption ( $59 \pm 8 \%, p>0.9999$, n.s.). Also, the inner membrane uncoupler carbonyl cyanide m-chlorophenylhydrazone (CCCP) did not increase oxygen consumption ( $91 \pm 6 \%, p>0.9999$, n.s.), because mitochondria in mouse brain seem to use oxygen at maximal rate that cannot be further increased by uncouplers, as also shown recently by others (Dias et al., 2018). Surprisingly, only KCN increased the redox ratio of $\mathrm{SNc}$ DaNs (Fig. 4A; redox ratio rotenone control: $0.37 \pm 0.09$, rotenone: $0.43 \pm 0.08$; antimycin A control: $0.50 \pm 0.07$, antimycin A: $0.45 \pm 0.04 ; \mathrm{KCN}$ control: $0.54 \pm 0.05$, $\mathrm{KCN}: 0.90 \pm 0.09, p=0.0004)$, indicating that the level of GSH in the matrix is decreased by the inhibition of COX. Importantly, inhibition of complex I and III by rotenone and antimycin A, respectively, which is established to result in pronounced production of ROS (Murphy, 2009), did not change this ratio.

Calcium influx is responsible for the high redox ratio of vulnerable $\mathrm{SNc}$ DaNs

2PLSM experiments showed that, in control mice, both VTA and SNc DaNs display almost identical mitochondrial redox ratios (Fig. $4 B$; VTA: $0.54 \pm 0.05$, SNc: $0.50 \pm 0.07, p>0.9999$, n.s.). Neither blockade of plasma membrane calcium 
channels by the selective inhibitor isradipine, nor inhibition of the mitochondrial calcium uniporter (MCU) with Ru360 induced changes in SNc and VTA DaNs of control animals $(\mathrm{SNc}+300 \mathrm{nM}$ isradipine $0.26 \pm 0.04, p>0.9999$, n.s.; VTA +300 $\mathrm{nM}$ isradipine $0.62 \pm 0.04, p>0.9999$, n.s.; SNc $20 \mu \mathrm{M}$ Ru360 $0.42 \pm 0.05, p>$ 0.9999, n.s.; VTA $20 \mu \mathrm{M}$ Ru360 $0.57 \pm$ $0.07, p>0.9999$, n.s.).

Importantly, there was a much higher redox ratio in MitoPark SNc DaNs (Fig. $4 B ; 0.90 \pm 0.08$ ) at the age of 12 weeks, i.e., at the onset of neurodegeneration, compared with MitoPark VTA DaNs (0.49 \pm $0.06, p=0.0009)$, but also compared with control SNc DaNs $(p=0.0004)$. This high redox ratio was robustly decreased in $\mathrm{Mi}$ toPark SNc when treating sections with isradipine $(0.45 \pm 0.05, p<0.0001)$, but no effect was seen in MitoPark VTA DaNs $(0.44 \pm 0.05, p>0.9999$, n.s.). Also, when MitoPark midbrain sections were incubated with Ru360, the redox ratio of SNc DaNs was again significantly lowered $(0.42 \pm 0.05, p=0.0010)$.

In conclusion, an elevated redox ratio, indicating a low GSH-GSSG ratio in the mitochondrial matrix, was found to be a hallmark of SNc, but not VTA DaNs in MitoPark mice, preceding the onset of severe neurodegeneration. This high redox ratio could be rescued by reducing neuronal as well as mitochondrial calcium influx.

\section{Mitochondrial membrane potential is hyperpolarized in MitoPark SNc DaNs and is further elevated when calcium influx is blocked}

The electrochemical potential of the inner mitochondrial membrane was assessed in midbrain sections loaded with TMRM, to better understand how mitochondrial dysfunction affects the redox ratio. Initial experiments showed that, quite surprisingly, the TMRM signal was lower in the somata of midbrain neurons compared with the surrounding tissue (Fig. 5A), in contrast to the higher signal for COXI protein (Fig. 2A), indicating that mitochondria in the somata have a lower inner membrane potential than those in other cell types and neurites. The mitochondrial network was clearly visualized by TMRM as shown in mouse fibroblasts (Fig. $5 B$ ). As expected, the TMRM signal of identified DaNs, but also of mitochondria in surrounding neurites, was dramatically reduced by KCN (Fig. $5 C)$. Tetramethylrhodamine ethyl ester (TMRE), another fluorescent dye sensitive to the inner membrane potential displayed a signal similar to TMRM and its intensity was likewise decreased by KCN (Fig. 5-1, available at https://doi.org/10.1523/ JNEUROSCI.1345-19.2019.f5-1). It was not possible to decrease these signals by the uncoupler CCCP, as usually used as a control, again probably because of its high lipophilicity and the myelin rich brain sections. Therefore, we decided to use the deflection of the TMRM signal upon maximal RC inhibition by $\mathrm{KCN}$ as a convenient readout for the actual inner mitochondrial membrane potential present in situ, before addition of KCN. VTA and $\mathrm{SNc} \mathrm{DaNs}$ of control mice revealed a similar $\triangle \mathrm{TMRM}-\mathrm{F}_{\mathrm{KCN}}$ value (Fig. 5D; SNc: $40.7 \pm 5.1$; VTA: $45.1 \pm 3.9, p>0.9999$, n.s.), indicating that the inner mitochondrial membrane potential is similar in these DaN populations. In addition, there was no difference in $\triangle$ TMRM- $\mathrm{F}_{\mathrm{KCN}}$ between control $(45.1 \pm 3.9)$ and MitoPark VTA DaNs $(39.7 \pm 4.2, p=0.3670$, n.s.), indicating that the mitochondrial membrane potential remained similar in the latter neurons, even in the presence of severe mitochondrial dysfunction. Interestingly, inhibition of complex IV by $\mathrm{KCN}$ led to an increase of $\triangle \mathrm{TMRM}-\mathrm{F}_{\mathrm{KCN}}$ in MitoPark SNC DaNs $(53.0 \pm 2.5)$ compared with MitoPark VTA (39.7 \pm 4.2 , $p=0.0278)$ and control SNc DaNs $(40.7 \pm 5.1, p=0.0352)$. This quite unexpectedly indicates that a high mitochondrial 
A

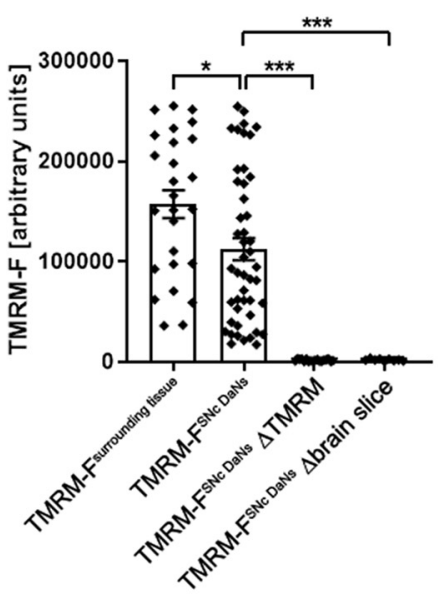

C
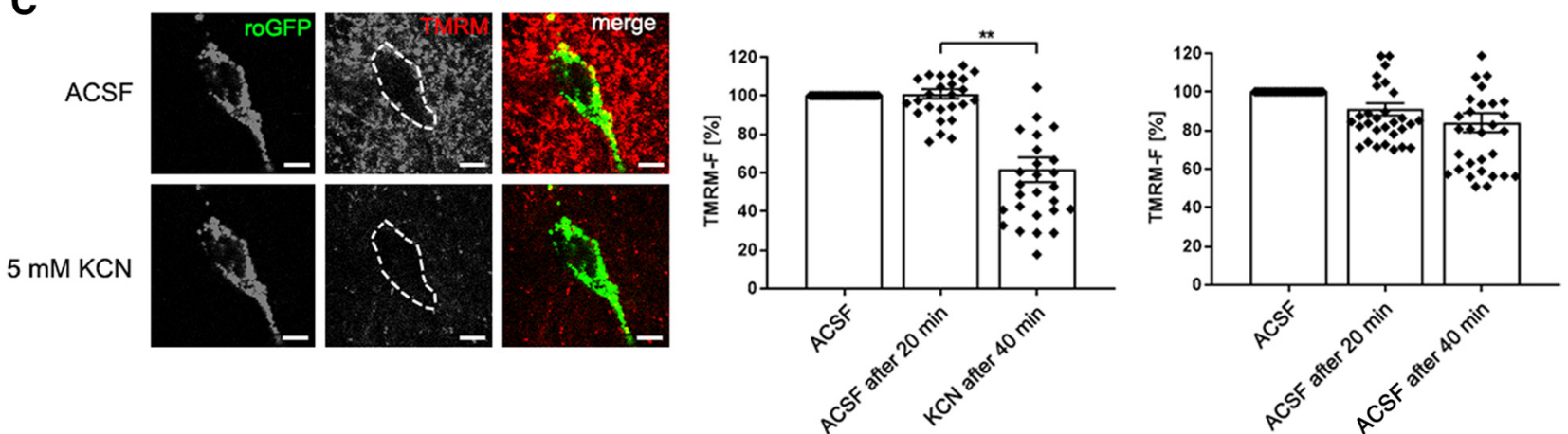

D

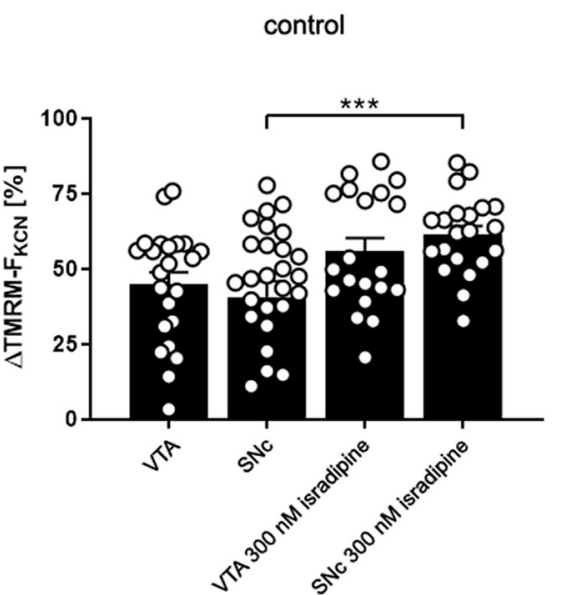

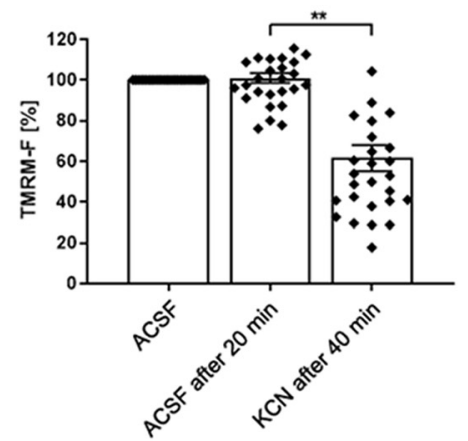

B

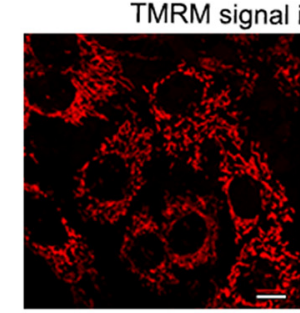

conventional

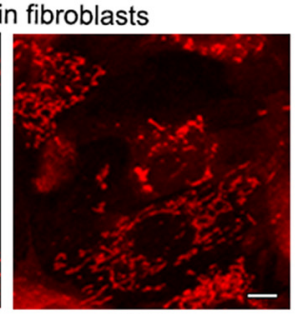

2PLSM

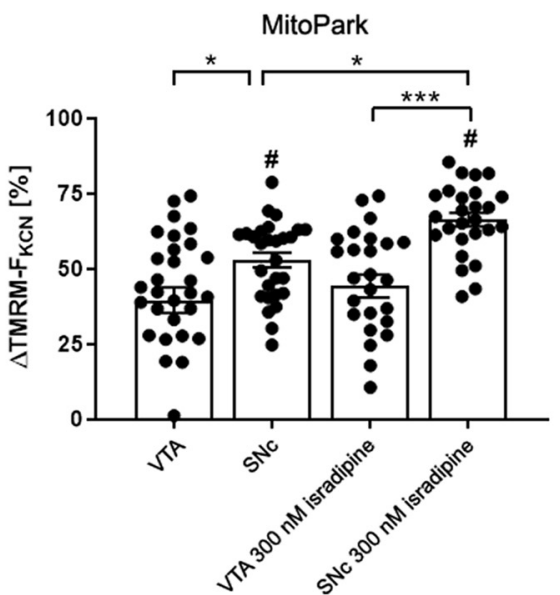

Figure 5. KCN induces an increase of $\triangle T M R M-F_{K C N}$ in MitoPark SNc DaNs. $A$, Quantitative data presenting a high fluorescent TMRM signal in the surrounding of cell somata and midbrain DaNs compared with DaNs from sections that were not loaded with TMRM and ACSF containing TMRM without tissue, respectively. $\boldsymbol{B}$, TMRM visualizes the mitochondrial network in mouse fibroblasts. Pictures were taken by using both conventional fluorescent microscope and 2PLSM. Scale bar, $10 \mu \mathrm{m}$. C, TMRM signal of a mito-roGFP expressing midbrain DaN before and after application of KCN. Scale bar, $10 \mu \mathrm{m}$. KCN (5 mM) induced a significant reduction of the TMRM signal in the soma of DaNs. $\boldsymbol{D}$, Reduction of the TMRM signal after KCN application was used to calculate the difference between TMRM fluorescence before and after KCN $\left(\triangle T\right.$ TMRM- $F_{K C N}=T M R M-F_{A C S F}, 20$ min $-T M R M-F_{K C N}, 40$ min $)$. Low TMRM signal intensities induced by $K C N$ are reflected by high $\Delta T M R M-F_{K C N}$ values. A high $\triangle T M R M-F_{K C N}$ value, in turn, represents a high mitochondrial membrane potential. $\triangle T M R M-F_{K C N}$ did not differ between VTA and SNc DaNs in control animals. However, in MitoPark mice, SNc DaNs showed a significantly higher $\triangle T$ TMRM- KCN $_{\text {CN }}$ deflection compared with MitoPark VTA and control SNc DaNs. Administration of KCN to midbrain sections pre-incubated with $300 \mathrm{nM}$ isradipine led to a significant elevation of $\triangle \mathrm{TMRM}-\mathrm{F}_{\mathrm{KCN}}$ in control and MitoPark SNc DaNs. In contrast, the use of isradipine did not alter the TMRM signal in both control and MitoPark VTA DaNs. \# indicates differences between control and MitoPark mice. Data are presented as mean \pm SEM. (Control VTA: $n=23$ neurons, MitoPark VTA: $n=31$ neurons, control VTA $+300 \mathrm{nM}$ isradipine: 20 neurons, MitoPark VTA $+300 \mathrm{nM}$ isradipine: $n=26$ neurons, control SNc: $n=28$ neurons, MitoPark SNc: $n=28$ neurons, control SNc $+300 \mathrm{nM}$ isradipine: $n=21$ neurons, MitoPark SNc +300 nM isradipine: $n=26$ neurons, $3-6$ mice per group; ${ }^{*} p<0.05,{ }^{* *} p<0.01,{ }^{* * *} p<0.001, \# p<0.05$ ).

inner membrane potential was present in SNc DaNs of MitoPark mice in situ.

Last, L-type plasma membrane calcium channels were blocked by isradipine to investigate whether and how the elevated mitochondrial membrane potential of MitoPark SNc DaNs is affected by calcium fluxes. Isradipine induced a significant increase of $\triangle \mathrm{TMRM}-\mathrm{F}_{\mathrm{KCN}}$ in control as well as in MitoPark SNc DaNs (Fig. $5 D$; control $+300 \mathrm{~nm}$ isradipine: $61.5 \pm 2.9, p=0.0052$; MitoPark $+300 \mathrm{~nm}$ isradipine: $66.4 \pm 2.3, p=0.0392$ ), but not in VTA DaNs, showing that the mitochondrial membrane potential 
in SNc DaNs of both control and MitoPark mice is further elevated when cytosolic calcium influx is inhibited. This suggests that a high mitochondrial membrane potential is established in SNc DaNs of control, but surprisingly also in MitoPark mice, to electrogenically remove and thus buffer cytosolic calcium, even when RC function is severely impaired, and consequently reaches an even higher maximal value when calcium influx is blocked.

\section{Discussion}

To answer the question how mitochondrial impairment leads to the selective degeneration of SNc DaNs, the mitochondrial redox ratio and the inner membrane potential was analyzed in MitoPark mice with preferential degeneration of the nigrostriatal system, similar to patients (Hirsch et al., 1988; Miller et al., 1997; Damier et al., 1999; Fig. 1A,D). COXI-expression was reduced to the same degree in VTA and SNc, and neurons with low COX activity were detected in both midbrain regions of MitoPark mice (Fig. 2 ), showing that the respiratory chain was affected to a similar extent. Substantial loss of COX did not lead to significant neuron death at 12 weeks (compare Figs. $1 D, 2$ ), implying that other factors than simply energy-deprivation are involved.

Calcium-binding proteins buffer excessive cytosolic calcium, shape calcium transients and contribute to calcium homeostasis (Baimbridge et al., 1992). In PD patients, SNc with few Cb-D28kexpressing DaNs suffers more from neuron loss than the $\mathrm{Cb}$ D28k-enriched VTA (Yamada et al., 1990; German et al., 1992; Reyes et al., 2012). Supporting these results, colocalization experiments of TH and Cb-D28k in MPTP-treated mice revealed predominant survival of calbindin-positive DaNs, suggesting that the presence of calbindin confers protection (Liang et al., 1996). Indeed, also our experiments revealed more calbindin-expressing DaNs remaining in both regions in 12- and 14-week-old MitoPark mice, and significantly more in SNc of 20 -week-old MitoPark mice (Fig. 3B). Interestingly, the calbindin mRNA content in pooled single substantia nigra DaNs from $\mathrm{PD}$ patients was found to be sixfold higher compared with healthy individuals (Schiemann et al., 2012), potentially indicating a response to mitochondrial defects. In summary, our colocalization experiments show that calbindin may render midbrain DaNs more resistant against neurodegeneration induced by mitochondrial dysfunction.

The substantia nigra of PD patients contains high levels of oxidized and damaged molecules (Dexter et al., 1994; Alam et al., 1997a,b), correlating with low concentrations of the ROSscavenging GSH molecule (Sian et al., 1994). Thus, mtDNA deletions leading to mitochondrial dysfunction, a high calcium load, and oxidative stress due to changes in the antioxidant defense system might be causally linked and ultimately lead to SNc DaN death.

Inhibitors were applied to midbrain sections to investigate whether and how impaired activity of the different RC complexes results in changes of the redox ratio (Fig. $4 A$ ). Despite reducing oxygen consumption, as expected (Fig. 4-3, available at https:// doi.org/10.1523/JNEUROSCI.1345-19.2019.f4-3), neither antimycin A nor rotenone altered the mitochondrial redox ratio of DaNs. Superoxide $\left(\mathrm{O}_{2}^{--}\right)$is increased by the complex III inhibitor antimycin A (Zhang et al., 1998) or the complex I inhibitor rotenone (Kushnareva et al., 2002), summarized by Murphy (2009), in SNc DaNs at even lower concentrations than used by us (Freestone et al., 2009). Therefore, the mito-roGFP signal is not sensitive to increased ROS production from RC complexes and our data make ROS rather unlikely as the cause of neuron death.

In contrast, $\mathrm{KCN}$ considerably increased the redox ratio (Fig. $4 A$ ). KCN results in increased autofluorescence in substantia nigra DaNs (Tucker et al., 2016), which is generally used as a readout for enhanced levels of reduced $\mathrm{NAD}(\mathrm{P}) \mathrm{H}$. Elevated $\mathrm{NAD}(\mathrm{P}) \mathrm{H}$ should increase the GSH-GSSG ratio (Nelson and Cox, 2005), which should lower the redox ratio (Dooley et al., 2004). However, our high redox ratio after KCN implies that inhibition of complex IV decreases levels of GSH in DaNs. We postulate that the pool of $\mathrm{NAD}(\mathrm{P}) \mathrm{H}$ in mitochondria is slowly consumed upon inhibition, without being further replenished by the Krebs cycle dehydrogenases.

After having established these relations, the redox-ratio was analyzed in MitoPark DaNs (Fig. 4B) at the age of 12 weeks, before widespread neuron death, but with severe COX deficiency (compare Figs. 1D, 2). SNc DaNs, but not VTA DaNs of MitoPark mice presented with an increased redox ratio, similar to $\mathrm{KCN}$ treatment, showing that additional, SNc-specific factors must account for this outcome. Because isradipine rescued the elevated redox ratio in MitoPark SNc DaNs (Fig. 4B), we postulate that calcium influx through $\mathrm{Ca}_{\mathrm{v}} 1.3$ channels (Chan et al., 2007; Guzman et al., 2009; Ortner et al., 2017) is responsible for mitochondrial "relative oxidation" in mitochondrially impaired SNc DaNs. Isradipine did not decrease the redox ratio in VTA neurons, since their pacemaking activity is predominantly driven by sodium channels (Khaliq and Bean, 2010).

Although isradipine at $300 \mathrm{nM}$, as we used, has been shown to completely block pacemaking by ablating $\mathrm{Ca}_{\mathrm{v}} 1.3$-mediated calcium influx in SNc DaNs (Ortner et al., 2017), it remains a matter of debate to which extent the magnitude of intracellular calcium is altered by this inhibitor, as indicated by fluorescent calcium probes: Isradipine at lower concentrations (30 nM) did not alter somatic calcium fluctuations (Ortner et al., 2017), whereas higher levels of isradipine $(5 \mu \mathrm{M})$ were sufficient to minimize dendritic calcium oscillations in SNc DaNs (Guzman et al., 2009). Blockade of calcium-driven pacemaking may significantly lower the energy demand of neurons, which may have caused the observed changes in mito-roGFP fluorescence. However, Ru360, the inhibitor of the mitochondrial calcium uniporter MCU, also reduced the redox ratio in MitoPark SNc DaNs (Fig. 4B), which was also observed in dendrites of SNc DaNs in control mice (Guzman et al., 2010), but not in their somata. Thus, in our hands, reduction of mitochondrial calcium uptake by Ru360 is not sufficient to reduce the redox ratio in functional mitochondria, whereas it does so in DaNs with a defective respiratory chain.

Elevated mitochondrial calcium leads to an increased rate of production of NADH by enhancing the activity of dehydrogenases and thus Krebs cycle flux (Denton, 2009), which should result in elevated GSH/GSSG. However, in SNc DaNs of MitoPark mice, reduction of mitochondrial calcium influx resulted in a decrease of the redox ratio and thus high levels of mitochondrial GSH.

In addition, and counterintuitively, although complex IV was reduced in both DaN types before the onset of neuron death (Fig. 2), MitoPark SNc DaNs had maintained a high mitochondrial inner membrane potential (Fig. 5D), even higher than SNc DaNs in controls. We postulate that this is achieved by bringing in a net negative charge by importing $\mathrm{ATP}^{4-}$, produced by glycolysis, from the cytosol via the adenine nucleotide transporter. ATP is hydrolyzed by ATP synthase operating in reverse mode, followed by export of $\mathrm{ATP}^{2-}+\mathrm{P}_{\mathrm{i}}{ }^{-}$. This mechanism of generating an inner membrane potential is well established in cell lines lacking mtDNA and thus a functioning respiratory chain (Buchet and Godinot, 1998; Appleby et al., 1999), however has not yet been shown in vivo to our knowledge. RC deficient SNc DaNs in MitoPark mice might maintain a high inner membrane potential, 
even at the expense of precious glycolytic ATP, to be able to pump calcium from the cytosol into the negative matrix via MCU. This is substantiated by our finding that inhibiting calcium influx through plasma membrane channels by isradipine further hyperpolarizes the inner membrane potential, both in control as well as in MitoPark mice (Fig. 5D), because, under this condition, the depolarizing cation influx into the matrix is blocked. In conclusion, even under conditions of a severe respiratory chain dysfunction, $\mathrm{SNc}$ DaNs in MitoPark mice maintain a high inner membrane potential to preserve calcium homeostasis.

The question remains how a high inner membrane potential, driving a constant calcium influx into the matrix, relates to the redox system changes we observed. The drop of the redox ratio after isradipine or Ru360 (Fig. 4B) shows that calcium influx contributed to the reduced GSH levels in SNc DaNs of MitoPark mice. Mammalian mitochondria contain two isocitrate dehydrogenase (IDH) isoforms, specific for $\mathrm{NAD}^{+}$(IDH3) and NADP ${ }^{+}$ (IDH2), respectively, which catalyze the conversion of isocitrate to $\alpha$-ketoglutarate ( $\alpha$-KG; Denton, 2009). Importantly, calcium is known to increase the activity of only IDH3, by lowering its $\mathrm{K}_{\mathrm{m}}$ for isocitrate (Denton et al., 1978; Rutter and Denton, 1988, 1989; Denton, 2009; Llorente-Folch et al., 2015). Therefore, mitochondrial calcium influx would enhance IDH3, but not IDH2 activity, with a resultant decrease in NADPH generation. We therefore hypothesize that the blockage of mitochondrial calcium influx by isradipine and Ru360 in our studies has decreased the activity of IDH3, thereby enhancing NADPH generation by IDH2, resulting in a normalization of the redox ratio. Alternatively, the teams of Lieberman et al., 2017 have shown in primary mouse DaNs that the mitochondrial toxin $\mathrm{MPP}^{+}$activates a cascade of increased cytosolic dopamine and calcium, followed by an elevation of mitochondrial calcium and activation of mitochondrial nitric oxide synthase, so generation of NO may also contribute to the disturbed mitochondrial redox system.

In summary, we hypothesize that mitochondrial dysfunction in $\mathrm{SNc} \mathrm{DaNs}$, in combination with their high mitochondrial calcium load, in contrast to the VTA, impairs the mitochondrial antioxidant defense system, which finally promotes their preferential degeneration.

\section{References}

Alam ZI, Daniel SE, Lees AJ, Marsden DC, Jenner P, Halliwell B (1997a) Oxidative DNA damage in the parkinsonian brain: an apparent selective increase in 8-hydroxyguanine levels in substantia nigra. J Neurochem 69:1196-1203.

Alam ZI, Jenner A, Daniel SE, Lees AJ, Cairns N, Marsden CD, Jenner P, Halliwell B (1997b) A generalised increase in protein carbonyls in the brain in Parkinson's but not incidental Lewy body disease. J Neurochem 69:1326-1329.

Appleby RD, Porteous WK, Hughes G, James AM, Shannon D, Wei YH, Murphy MP (1999) Quantitation and origin of the mitochondrial membrane potential in human cells lacking mitochondrial DNA. Eur J Biochem 262:108-116.

Baimbridge KG, Celio MR, Rogers JH (1992) Calcium-binding proteins in the nervous system. Trends Neurosci 15:303-308.

Bender A, Krishnan KJ, Morris CM, Taylor GA, Reeve AK, Perry RH, Jaros E, Hersheson JS, Betts J, Klopstock T, Taylor RW, Turnbull DM (2006) High levels of mitochondrial DNA deletions in substantia nigra neurons in aging and Parkinson disease. Nat Genet 38:515-517.

Betarbet R, Sherer TB, MacKenzie G, Garcia-Osuna M, Panov AV, Greenamyre JT (2000) Chronic systemic pesticide exposure reproduces features of Parkinson's disease. Nat Neurosci 3:1301-1306.

Bolam JP, Pissadaki EK (2012) Living on the edge with too many mouths to feed: why dopamine neurons die. Mov Disord 27:1478-1483.

Braak H, Ghebremedhin E, Rüb U, Bratzke H, Del Tredici K (2004) Stages in the development of Parkinson's disease-related pathology. Cell Tissue Res 318:121-134.
Buchet K, Godinot C (1998) Functional F1-ATPase essential in maintaining growth and membrane potential of human mitochondrial DNA-depleted $\rho^{\circ}$ cells. J Biol Chem 273:22983-22989.

Burbulla LF, Song P, Mazzulli JR, Zampese E, Wong YC, Jeon S, Santos DP, Blanz J, Obermaier CD, Strojny C, Savas JN, Kiskinis E, Zhuang X, Krüger R, Surmeier DJ, Krainc D (2017) Dopamine oxidation mediates mitochondrial and lysosomal dysfunction in Parkinson's disease. Science 357:1255-1261.

Chan CS, Guzman JN, Ilijic E, Mercer JN, Rick C, Tkatch T, Meredith GE, Surmeier DJ (2007) "Rejuvenation" protects neurons in mouse models of Parkinson's disease. Nature 447:1081-1086.

Cortopassi GA, Shibata D, Soong NW, Arnheim N (1992) A pattern of accumulation of a somatic deletion of mitochondrial DNA in aging human tissues. Proc Natl Acad Sci U S A 89:7370-7374.

Damier P, Hirsch EC, Agid Y, Graybiel AM (1999) The substantia nigra of the human brain: II. Patterns of loss of dopamine-containing neurons in Parkinson's disease. Brain 122:1437-1448.

Dauer W, Przedborski S (2003) Parkinson's disease: mechanisms and models. Neuron 39:889-909.

de Lau LML, Breteler MM (2006) Epidemiology of Parkinson's disease. Lancet Neurol 5:525-535.

Denton RM (2009) Regulation of mitochondrial dehydrogenases by calcium ions. Biochim Biophys Acta 1787:1309-1316.

Denton RM, Richards DA, Chin JG (1978) Calcium ions and the regulation of NAD+-linked isocitrate dehydrogenase from the mitochondria of rat heart and other tissues. Biochem J 176:899-906.

Dexter DT, Holley AE, Flitter WD, Slater TF, Wells FR, Daniel SE, Lees AJ, Jenner P, Marsden CD (1994) Increased levels of lipid hydroperoxides in the parkinsonian substantia nigra: an HPLC and ESR study. Mov Disord 9:92-97.

Dias C, Lourenço CF, Barbosa RM, Laranjinha J, Ledo A (2018) Analysis of respiratory capacity in brain tissue preparations: high-resolution respirometry for intact hippocampal slices. Analyt Biochem 551:43-50.

Dölle C, Flønes I, Nido GS, Miletic H, Osuagwu N, Kristoffersen S, Lilleng PK, Larsen JP, Tysnes OB, Haugarvoll K, Bindoff LA, Tzoulis C (2016) Defective mitochondrial DNA homeostasis in the substantia nigra in parkinson disease. Nat Commun 7:13548.

Dooley CT, Dore TM, Hanson GT, Jackson WC, Remington SJ, Tsien RY (2004) Imaging dynamic redox changes in mammalian cells with green fluorescent protein indicators. J Biol Chem 279:22284-22293.

Dorph-Petersen KA, Nyengaard JR, Gundersen HJ (2001) Tissue shrinkage and unbiased stereological estimation of particle number and size. J Microsc 204:232-246.

Dragicevic E, Poetschke C, Duda J, Schlaudraff F, Lammel S, Schiemann J, Fauler M, Hetzel A, Watanabe M, Lujan R, Malenka RC, Striessnig J, Liss B (2014) Cav1.3 channels control D2-autoreceptor responses via NCS-1 in substantia nigra dopamine neurons. Brain 137:2287-2302.

Dryanovski DI, Guzman JN, Xie Z, Galteri DJ, Volpicelli-Daley LA, Lee VM, Miller RJ, Schumacker PT, Surmeier DJ (2013) Calcium entry and $\alpha$-synuclein inclusions elevate dendritic mitochondrial oxidant stress in dopaminergic neurons. J Neurosci 33:10154-10164.

Duda J, Pötschke C, Liss B (2016) Converging roles of ion channels, calcium, metabolic stress, and activity pattern of substantia nigra dopaminergic neurons in health and Parkinson's disease. J Neurochem 139: $156-178$.

Ekstrand MI, Terzioglu M, Galter D, Zhu S, Hofstetter C, Lindqvist E, Thams S, Bergstrand A, Hansson FS, Trifunovic A, Hoffer B, Cullheim S, Mohammed AH, Olson L, Larsson NG (2007) Progressive parkinsonism in mice with respiratory-chain-deficient dopamine neurons. Proc Natl Acad Sci U S A 104:1325-1330.

Freestone PS, Chung KK, Guatteo E, Mercuri NB, Nicholson LF, Lipski J (2009) Acute action of rotenone on nigral dopaminergic neurons: involvement of reactive oxygen species and disruption of $\mathrm{Ca}^{2+}$ homeostasis. Eur J Neurosci 30:1849-1859.

German DC, Manaye KF, Sonsalla PK, Brooks BA (1992) Midbrain dopaminergic cell loss in Parkinson's disease and MPTP-induced parkinsonism: sparing of calbindin-D28k-containing cells. Ann N Y Acad Sci 648:42-62.

Glaser J, Greene G, Hendricks S (2007) Stereology for biological research with focus on neurobiology. Williston, VT: MBF.

Gundersen HJ, Bagger P, Bendtsen TF, Evans SM, Korbo L, Marcussen N, Møller A, Nielsen K, Nyengaard JR, Pakkenberg B (1988) The new ste- 
reological tools: disector, fractionator, nucleator and point sampled intercepts and their use in pathological research and diagnosis. APMIS 96:857-881.

Guzman JN, Sánchez-Padilla J, Chan CS, Surmeier DJ (2009) Robust pacemaking in substantia nigra dopaminergic neurons. J Neurosci 29:11011-11019.

Guzman JN, Sanchez-Padilla J, Wokosin D, Kondapalli J, Ilijic E, Schumacker PT, Surmeier DJ (2010) Oxidant stress evoked by pacemaking in dopaminergic neurons is attenuated by DJ-1. Nature 468:696-700.

Hirsch E, Graybiel AM, Agid YA (1988) Melanized dopaminergic neurons are differentially susceptible to degeneration in Parkinson's disease. Nature 334:345-348.

Howard VC, Reed MR (2005) The optical fractionator. In: Unbiased stereology: three dimensional measurement in microscopy, Ed 2, pp 95-96. Milton Park, UK: Taylor \& Francis.

Khaliq ZM, Bean BP (2010) Pacemaking in dopaminergic ventral tegmental area neurons: depolarizing drive from background and voltagedependent sodium conductances. J Neurosci 30:7401-7413.

Kraytsberg Y, Kudryavtseva E, McKee AC, Geula C, Kowall NW, Khrapko K (2006) Mitochondrial DNA deletions are abundant and cause functional impairment in aged human substantia nigra neurons. Nat Genet 38: $518-520$.

Kushnareva Y, Murphy AN, Andreyev A (2002) Complex I-mediated reactive oxygen species generation: modulation by cytochrome $\mathrm{c}$ and $\mathrm{NAD}(\mathrm{P})+$ oxidation-reduction state. Biochem J 368:545-553.

Liang CL, Sinton CM, Sonsalla PK, German DC (1996) Midbrain dopaminergic neurons in the mouse that contain calbindin-D28kExhibit reduced vulnerability to MPTP-induced neurodegeneration. Neurodegeneration 5:313-318.

Lieberman OJ, Choi SJ, Kanter E, Saverchenko A, Frier MD, Fiore GM, Wu M, Kondapalli J, Zampese E, Surmeier DJ, Sulzer D, Mosharov EV (2017) $\alpha$-Synuclein-dependent calcium entry underlies differential sensitivity of cultured SN and VTA dopaminergic neurons to a parkinsonian neurotoxin. eNeuro 4:ENEURO.0167-17.2017.

Liss B, Roeper J (2008) Individual dopamine midbrain neurons: functional diversity and flexibility in health and disease. Brain Res Rev 58:314-321.

Liss B, Haeckel O, Wildmann J, Miki T, Seino S, Roeper J (2005) -ATP channels promote the differential degeneration of dopaminergic midbrain neurons. Nat Neurosci 8:1742-1751.

Llorente-Folch I, Rueda CB, Pardo B, Szabadkai G, Duchen MR, Satrustegui J (2015) The regulation of neuronal mitochondrial metabolism by calcium. J Physiol 593:3447-3462.

Lotter S, Aradjanski M, Hermans S, Dogan SA, Trifunovic A, Wang S, Wibom R, Rugarli E, Trifunovic A (2017) DARS2 protects against neuroinflammation and apoptotic neuronal loss, but is dispensable for myelin producing cells. Hum Mol Genet 26:4181-4189.

Ma SY, Longo F, Röyttä M, Collan Y (2003) Modern stereological evaluation in the aging human substantia nigra. Image Anal Stereol 22:73-80.

Meissner C, Bruse P, Mohamed SA, Schulz A, Warnk H, Storm T, Oehmichen M (2008) The 4977 bp deletion of mitochondrial DNA in human skeletal muscle, heart and different areas of the brain: a useful biomarker or more? Exp Gerontol 43:645-652.

Miller GW, Staley JK, Heilman CJ, Perez JT, Mash DC, Rye DB, Levey AI (1997) Immunochemical analysis of dopamine transporter protein in Parkinson's disease. Ann Neurol 41:530-539.

Murphy MP (2009) How mitochondria produce reactive oxygen species. Biochem J 417:1-13.

Nelson DL, Cox MM (2005) Lehninger principles of biochemistry. New York: W.H. Freeman.

Neuhaus JF, Baris OR, Hess S, Moser N, Schröder H, Chinta SJ, Andersen JK, Kloppenburg P, Wiesner RJ (2014) Catecholamine metabolism drives generation of mitochondrial DNA deletions in dopaminergic neurons. Brain 137:354-365.

Neuhaus JF, Baris OR, Kittelmann A, Becker K, Rothschild MA, Wiesner RJ (2017) Catecholamine metabolism induces mitochondrial DNA deletions and leads to severe adrenal degeneration during aging. Neuroendocrinology 104:72-84.
Obeso JA, Stamelou M, Goetz CG, Poewe W, Lang AE, Weintraub D, Burn D, Halliday GM, Bezard E, Przedborski S, Lehericy S, Brooks DJ, Rothwell JC, Hallett M, DeLong MR, Marras C, Tanner CM, Ross GW, Langston JW, Klein C, et al. (2017) Past, present, and future of Parkinson's disease: a special essay on the 200th anniversary of the shaking palsy. Mov Disord 32:1264-1310.

Ortner NJ, Bock G, Dougalis A, Kharitonova M, Duda J, Hess S, Tuluc P, Pomberger T, Stefanova N, Pitterl F, Ciossek T, Oberacher H, Draheim HJ, Kloppenburg P, Liss B, Striessnig J (2017) Lower affinity of isradipine for L-type $\mathrm{Ca}^{2+}$ channels during substantia nigra dopamine neuronlike activity: implications for neuroprotection in Parkinson's disease. J Neurosci 37:6761-6777.

Pacelli C, Giguère N, Bourque MJ, Lévesque M, Slack RS, Trudeau LÉ (2015) Elevated mitochondrial bioenergetics and axonal arborization size are key contributors to the vulnerability of dopamine neurons. Curr Biol 25: $2349-2360$

Paxinos G, Franklin KB (2001) The mouse brain in stereotaxic coordinates. Academic Press, San Diego.

Philippart F, Destreel G, Merino-Sepúlveda P, Henny P, Engel D, Seutin V (2016) Differential somatic $\mathrm{Ca}^{2+}$ channel profile in midbrain dopaminergic neurons. J Neurosci 36:7234-7245.

Pickrell AM, Youle RJ (2015) The roles of PINK1, parkin, and mitochondrial fidelity in Parkinson's disease. Neuron 85:257-273.

Reeve A, Simcox E, Turnbull D (2014) Ageing and Parkinson's disease: why is advancing age the biggest risk factor? Ageing Res Rev 14:19-30.

Reyes S, Fu Y, Double K, Thompson L, Kirik D, Paxinos G, Halliday GM (2012) GIRK2 expression in dopamine neurons of the substantia nigra and ventral tegmental area. J Comp Neurol 520:2591-2607.

Rutter GA, Denton RM (1988) Regulation of NAD+-linked isocitrate dehydrogenase and 2-oxoglutarate dehydrogenase by $\mathrm{Ca}^{2+}$ ions within toluene-permeabilized rat heart mitochondria: interactions with regulation by adenine nucleotides and NADH/NAD + ratios. Biochem J 252:181-189.

Rutter GA, Denton RM (1989) The binding of $\mathrm{Ca}^{2+}$ ions to pig heart $\mathrm{NAD}+$-isocitrate dehydrogenase and the 2-oxoglutarate dehydrogenase complex. Biochem J 263:453-462.

Schiemann J, Schlaudraff F, Klose V, Bingmer M, Seino S, Magill PJ, Zaghloul KA, Schneider G, Liss B, Roeper J (2012) K-ATP channels in dopamine substantia nigra neurons control bursting and novelty-induced exploration. Nat Neurosci 15:1272-1280.

Sciacco M, Bonilla E (1996) Cytochemistry and immunocytochemistry of mitochondria in tissue sections. In: Methods in enzymology, Vol. 264, 509-521. New York: Academic,

Sian J, Dexter DT, Lees AJ, Daniel S, Agid Y, Javoy-Agid F, Jenner P, Marsden CD (1994) Alterations in glutathione levels in Parkinson's disease and other neurodegenerative disorders affecting basal ganglia. Ann Neurol 36:348-355.

Sterky FH, Lee S, Wibom R, Olson L, Larsson NG (2011) Impaired mitochondrial transport and Parkin-independent degeneration of respiratory chain-deficient dopamine neurons in vivo. Proc Natl Acad Sci U S A 108:12937-12942.

Sulzer D (2007) Multiple hit hypotheses for dopamine neuron loss in Parkinson's disease. Trends Neurosci 30:244-250.

Tucker KR, Cavolo SL, Levitan ES (2016) Elevated mitochondria-coupled $\mathrm{NAD}(\mathrm{P}) \mathrm{H}$ in endoplasmic reticulum of dopamine neurons. Mol Biol Cell 27:3214-3220.

Vevea JD, Alessi Wolken DM, Swayne TC, White AB, Pon LA (2013) Ratiometric biosensors that measure mitochondrial redox state and ATP in living yeast cells. J Vis Exp 50633.

Yamada T, McGeer PL, Baimbridge KG, McGeer EG (1990) Relative sparing in Parkinson's disease of substantia nigra dopamine neurons containing calbindin-D28K. Brain Res 526:303-307.

Zhang L, Yu L, Yu CA (1998) Generation of Superoxide Anion by Succinate-Cytochrome c Reductase from Bovine Heart Mitochondria. J Biol Chem 273:33972-33976. 